\title{
"Photobiomics": Can Light, Including Photobiomodulation, Alter the Microbiome?
}

\author{
Ann Liebert, PhD, ${ }^{1,2}$ Brian Bicknell, PhD, ${ }^{3}$ Daniel M. Johnstone, PhD, ${ }^{4}$ Luke C. Gordon, BEHons, BMedSc, ${ }^{4}$ \\ Hosen Kiat, MBBS, DMedSc, ${ }^{5,6}$ and Michael R. Hamblin, PhD ${ }^{7-9}$
}

\begin{abstract}
Objective: The objective of this review is to consider the dual effects of microbiome and photobiomodulation (PBM) on human health and to suggest a relationship between these two as a novel mechanism.

Background: PBM describes the use of low levels of visible or near-infrared (NIR) light to heal and stimulate tissue, and to relieve pain and inflammation. In recent years, PBM has been applied to the head as an investigative approach to treat diverse brain diseases such as stroke, traumatic brain injury (TBI), Alzheimer's and Parkinson's diseases, and psychiatric disorders. Also, in recent years, increasing attention has been paid to the total microbial population that colonizes the human body, chiefly in the gut and the mouth, called the microbiome. It is known that the composition and health of the gut microbiome affects many diseases related to metabolism, obesity, cardiovascular disorders, autoimmunity, and even brain disorders.

Materials and methods: A literature search was conducted for published reports on the effect of light on the microbiome.

Results: Recent work by our research group has demonstrated that PBM (red and NIR light) delivered to the abdomen in mice, can alter the gut microbiome in a potentially beneficial way. This has also now been demonstrated in human subjects.

Conclusions: In consideration of the known effects of PBM on metabolomics, and the now demonstrated effects of PBM on the microbiome, as well as other effects of light on the microbiome, including modulating circadian rhythms, the present perspective introduces a new term "photobiomics" and looks forward to the application of PBM to influence the microbiome in humans. Some mechanisms by which this phenomenon might occur are considered.
\end{abstract}

Keywords: photobiomodulation, microbiome, bacteria, metabolome

\section{Introduction to Light Therapy and the Microbiome}

$\mathbf{L}$ IGHT IS KNOWN TO have wide-ranging effects in multiple biological kingdoms, ${ }^{1}$ and has been used for many years as a therapeutic agent, although in recent years (in the modern era of pharmaceuticals) it has fallen from favor. Finsen received the Nobel Prize for Physiology or Medicine in 1903 for his work in treating cutaneous tuberculosis with UV light and smallpox with red light. ${ }^{2}$ Bright light therapy (phototherapy) is still the first-line therapy for seasonal affective disorder, for circadian rhythm misalignment, and is used for sleep disorders (including for Parkinson's disease ${ }^{3}$ ) and Alzheimer's disease at the Mayo clinic in the United States (https://www.mayoclinic.org/tests-procedures/light-therapy/

\footnotetext{
${ }^{1}$ Australasian Research Institute, Wahroonga, Australia.

${ }^{2}$ Department of Medicine, University of Sydney, Camperdown, Australia.

${ }^{3}$ Faculty of Health Sciences, Australian Catholic University, North Sydney, Australia.

${ }^{4}$ Discipline of Physiology, University of Sydney, Camperdown, Australia.

${ }^{5}$ Faculty of Medicine and Health Sciences, Macquarie University, Marsfield, Australia.

${ }^{6}$ Faculty of Medicine, University of New South Wales, Kensington, Australia.

${ }^{7}$ Wellman Center for Photomedicine, Massachusetts General Hospital, Boston, Massachusetts.

${ }_{9}^{8}$ Department of Dermatology, Harvard Medical School, Boston, Massachusetts.

${ }^{9}$ Harvard-MIT Division of Health Sciences and Technology, Cambridge, Massachusetts.
}

(C) Ann Liebert, et al., 2019; Published by Mary Ann Liebert, Inc. This Open Access article is distributed under the terms of the Creative Commons License (http://creativecommons.org/licenses/by/4.0), which permits unrestricted use, distribution, and reproduction in any medium, provided the original work is properly credited. 
about/pac-20384604). Bright light therapy has been suggested as a therapy for depression and other neuropsychiatric conditions ${ }^{4}$ and is currently under trial as a therapy for Parkinson's disease. ${ }^{5}$ Neonatal hyperbilirubinemia has been routinely treated since the 1970 s with blue light. Red light for the treatment of retinopathy of prematurity, caused by oxygen toxicity, is now being trialed, ${ }^{6-8}$ and could also be tested for methanol-induced retinal damage, diabetic retinopathy ${ }^{7}$ and age-related macular degeneration, ${ }^{9-11}$ and cognition. ${ }^{12}$ It is becoming increasingly apparent that daylight and circadian rhythms play an important part in many treatments. For example, the timing of therapy (chronotherapy) in cardiovascular disease influences therapeutic success ${ }^{13}$ and the position (sunny versus dull) of the patients in cardiac intensive care units who are recovering from myocardial infarction, influences their mortality and length of hospital stay. ${ }^{14}$

It has been recognized in recent years that the gut microbiome is inextricably linked with health and disease. The gut microbiome (whether healthy or not) has a profound effect on inflammation and cytokine production, production of metabolites, and direct vagal nerve stimulation. It is also recognized that there is a complex communication between the body and the various microbiomes within the body. It is the contention of the authors that light, and specifically photobiomodulation (PBM), can alter the microbiome, possibly through this communication.

Light can affect the microbiome indirectly through the daily circadian rhythm. The metabolome is intimately associated with chronobiology and hence with ambient light, ${ }^{13}$ with the circadian clock regulating levels of metabolites, including those from the microbiome, which in turn can affect metabolome. ${ }^{15}$ The effect of the circadian rhythm on the microbiome has been demonstrated $^{16-18}$ and the bacteria responsible for decreased gut integrity and increased lipopolysaccharide transport are upregulated in mice after disruption of the sleep/wake cycle. ${ }^{18}$ In addition to circadian rhythm, light also has an indirect effect on the microbiome through vitamin $\mathrm{D}$, produced by the action of sunlight on keratinocytes. Vitamin D is known to boost immune function by the induction of antimicrobial peptide genes and the regulation of tight junction proteins in the epithelial layer of the intestine ${ }^{19,20}$ and to maintain microbiome homeostasis and protect against colitis in mice, ${ }^{21}$ possibly by controlling inflammation. ${ }^{22}$ Vitamin D deficiency has been linked with such conditions as irritable bowel disease, obesity and diabetes, proinflammatory cytokines, intestinal barrier disturbance, ${ }^{23}$ and gut dysbiosis, ${ }^{22}$ and has been suggested to influence immune-mediated disease. ${ }^{24}$ Similarly, contaminants in food, such as fertilizers, pesticides, and herbicides, can have their toxicity increased by sunlight, ${ }^{25}$ which may also have an adverse effect on the microbiome.

It is also apparent that blue light-emitting diode (LED) screens and lights used at night can suppress melatonin secretion and affect circadian rhythms with consequent effects on health ${ }^{26}$ and it has also been demonstrated that red light (morning light) in humans can influence both leptin and ghrelin concentrations, ${ }^{27}$ which play a role in energy homeostasis, hunger, and satiety. Recently, Basha and colleagues $^{28}$ have shown that fluorescent lighting can affect the oxidative stress of rats and Boswell and colleagues have shown that fluorescent lighting can have effects on gene regulation and inflammatory processes, ${ }^{29}$ which have the potential to affect the microbiome.
We introduce the term "photobiomics" to characterize the combined effects of light (PBM or otherwise) on metabolomic factors, the microbiome, and the interaction between the two.

\section{Photobiomodulation}

Light therapy was, in a sense, rediscovered by Mester et al. who found that low-power laser light had a positive effect on wound healing and hair regrowth in mice. ${ }^{30} \mathrm{PBM}$ is the newly adopted consensus term to describe the therapeutic application of low levels of red and/or near-infrared (NIR) light to treat a multitude of different diseases and disorders. PBM used to be known as "low-level laser or light therapy," but the name was changed to reflect the increasing use of LEDs, the possibility of inhibition as well as stimulation, and to avoid the undefined nature of the term "low level", 31

The mechanisms of action of PBM have been widely investigated in recent years, and additional mechanistic information is still being discovered. Nevertheless, it is generally accepted that the single most important chromophore in the red and NIR regions of the spectrum is cytochrome $\mathrm{c}$ oxidase (CCO), which is unit IV of the mitochondrial respiratory chain. When CCO absorbs light, the enzyme activity is increased leading to increased electron transport, more oxygen consumption, higher mitochondrial membrane potential, and increased ATP production. ${ }^{32}$ Signaling molecules are produced, including a brief burst of reactive oxygen species (ROS), nitric oxide, cyclic AMP, and movements in intracellular calcium. These signaling molecules result in activation of a host of transcription factors, and changes in the expression of a multitude of gene products, including structural proteins, enzymes, and mediators of cell division and cell migration. ${ }^{32}$ Interestingly, a recent report has thrown into question the central role of $\mathrm{CCO}$ in the mechanism of PBM action. ${ }^{33}$

In addition to the proposed action of PBM on $\mathrm{CCO}$, and the consequent signaling, other mechanisms operate at a cellular and tissue level, including nonvisual phototransduction cascades involving opsins (OPN 1-5). Recent evidence has shown that blue $(415 \mathrm{~nm})$ and green $(540 \mathrm{~nm})$ light are absorbed by opsins that then trigger opening of transient receptor potential (TRP) calcium ion channels. ${ }^{34}$ The interaction between PBM and opsins in the skin has been reviewed by Khan and Arany. ${ }^{35}$ There is recent evidence that melanopsin (OPN4), found in the eye, is also present in adipocytes, ${ }^{36,37}$ throughout the brain, ${ }^{38}$ in skin cells, and blood vessels. ${ }^{39}$ Melanopsin is a tristable switch that can absorb in the red spectrum. ${ }^{40}$ Light penetrating the skull (sunlight and PBM) can alter melanopsin. $^{41}$ The $380 \mathrm{~nm}$ light is also absorbed by neuropsin (OPN5) in the skin, retina, and nervous system and light is absorbed in hair follicles by OPN2 and OPN3. Absorption by opsins results in downstream nonvisual phototransduction cascades, which in turn presumably influence protein conformation at the cell membrane and possibly cytoskeleton modulation cascades. ${ }^{42}$

Santana-Blank and Rodriguez-Santana ${ }^{43,44}$ have argued that the structure of water and its absorption of NIR is integral to PBM mechanisms. PBM, delivered as low-level laser, has been shown to have a dramatic effect on the cytoskeleton structure of nerve cells, with the rapid formation of transient varicosities, and consequent nerve blockade for 
pain relief. ${ }^{45-49}$ PBM also affects the cytoskeleton of other cells besides neurons, such as epithelial cells, ${ }^{50}$ keratinocytes, ${ }^{51}$ and fibroblasts, ${ }^{52}$ and has been shown to have effects on protein conformation, including calcium ion channels. ${ }^{53-55}$ PBM also has an effect on brain oscillation patterns, with changes to alpha, beta, gamma, delta, and theta waves in both mice $^{56}$ and humans ${ }^{57}$ (El Khoury, et al., unpublished observations) and effects on the default mode network. ${ }^{58}$

Many of the diseases treated by PBM are localized by nature and include orthopedic conditions, such as inflammation in joints and tendons, wounds, and fractures. In these applications, light is usually delivered as a spot (often from a focused laser beam) onto the affected area of tissue. The wavelengths employed are mostly in the red regions (630$680 \mathrm{~nm})$ or in the NIR region (780-940 nm), although longer wavelengths (980 and $1064 \mathrm{~nm}$ ) have also shown benefit. ${ }^{32}$ Power densities are usually in the region of $10-100 \mathrm{~mW} / \mathrm{cm}^{2}$, together with energy densities in the region of $4-50 \mathrm{~J} / \mathrm{cm}^{2}$. It is usual to use higher power densities and higher energy densities to treat lesions that are located deeper in the tissue, such as large joints, spine, and brain. Figure 1 gives a diagrammatic illustration of many disorders that have been treated by PBM.

In recent years there has been accumulating evidence that there are also significant systemic effects produced by PBM, whereby application of PBM to one part of the body promotes beneficial outcomes in remote tissues. The exact mechanisms underlying these systemic effects of PBM are not completely understood, but some hypotheses have been put forward. One such involves the absorption of light by muscle. The large mass of muscle that is exposed to light combined with the high numbers of mitochondria inside muscle cells, means that the resulting increase in metabo- lism can have effects on the whole body. Not only has PBM been shown to be important for increasing athletic performance, and encouraging recovery from strenuous exercise, ${ }^{59}$ but also the increased consumption of glucose, and the burning of fat goes some way to improving diabetes, metabolic syndrome, and countering obesity and systemic inflammation. ${ }^{60}$ In fact, the study of PBM and metabolomics is a nascent area of study. ${ }^{61}$ The use of PBM to treat cardiovascular diseases, such as hypertension, high cholesterol, disorders of circulation, clotting disorders is a still-emerging field. ${ }^{62}$

Given its important effects on mitochondria within cells that are irradiated, PBM may trigger a signaling system between mitochondria in peripheral cells and cells residing in the brain, ${ }^{63}$ facilitated by an unknown mediator termed a "mitokine". In Caenorhabditis elegans it has been shown that mitochondrial perturbations in one tissue type initiate a mitochondrial stress response in distal, seemingly unaffected tissues. ${ }^{64,65}$ Aside from the effects on mitochondria, PBM is also known to induce proliferation and migration of stem cells. ${ }^{32,66-69}$ It has been suggested that through this induction, PBM can mobilize stem cells that home specifically to damaged tissue to aid in repair. For example, in animal models, PBM applied to the tibia results in migration of stem cells and mitigation of damage in models of myocardial infarction $^{70-72}$ and Alzheimer's disease. ${ }^{73,74}$ Another possibility is that PBM treatment could remediate mitochondrial dysfunction in gut neurons, reinstating the complex bidirectional communication system between the enteric nervous system and the central nervous system (the gut/brain axis). This may have particular significance for neurodegenerative conditions, such as Alzheimer's and Parkinson's diseases, both of which involve early pathological abnormalities in the gut/brain axis. ${ }^{75-79}$
FIG. 1. Schematic illustration of the wide variety of human diseases and disorders that have been treated by PBM. PBM, photobiomodulation.

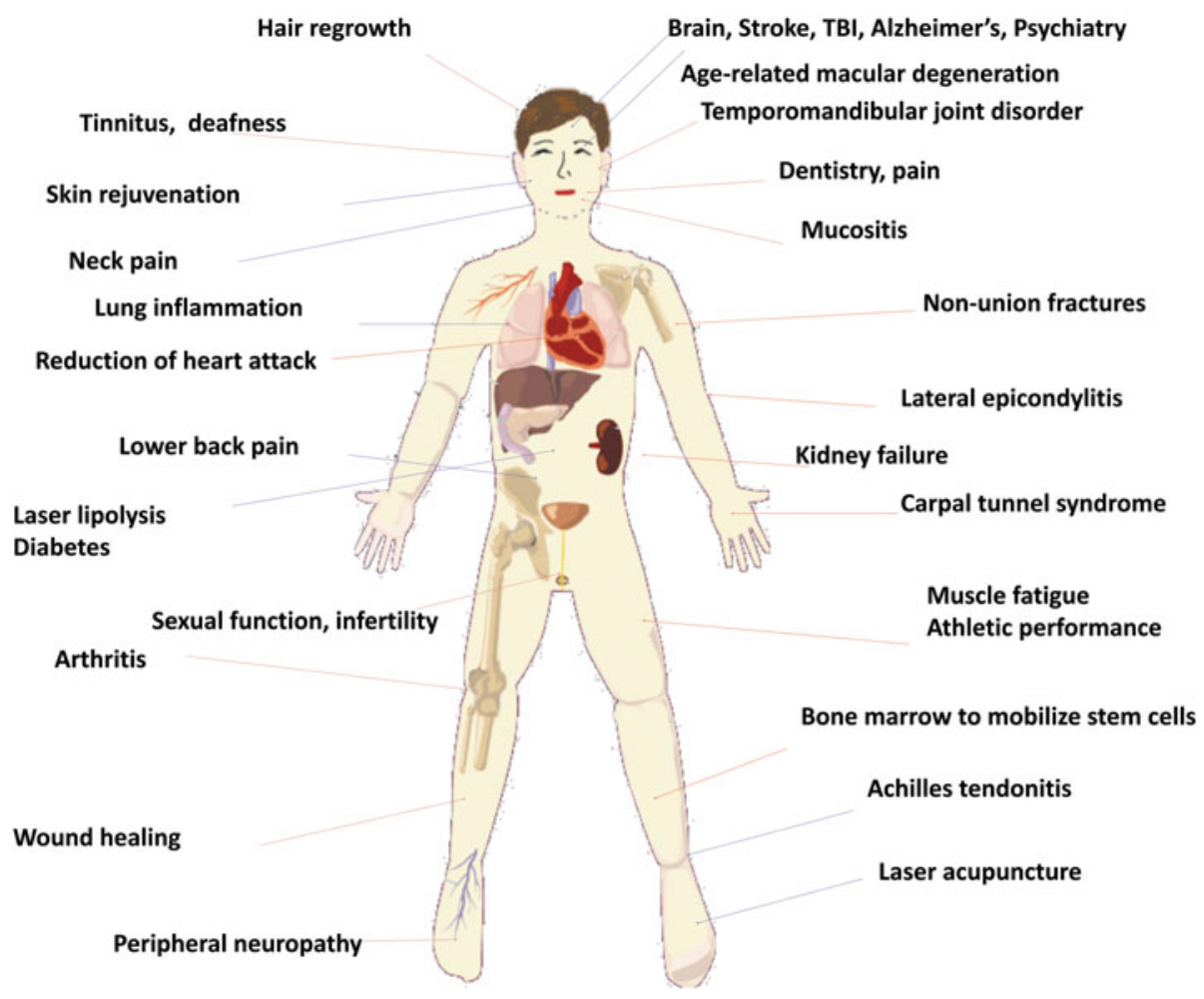


PBM has a pronounced effect on inflammatory processes by reducing oxidative stress, reducing proinflammatory cytokines, and changing macrophage phenotype. ${ }^{80}$ The local effect of PBM on inflammatory pathways most probably has systemic consequences. It is possible that circulating immune cells (mast cells, macrophages, etc.), stimulated by PBM, ${ }^{81-84}$ could transduce protective signals from distal tissues to sites of injury such as the brain, heart, or gut.

\section{Human Microbiome}

The human microbiome comprises many billions of bacteria, archaea, protists and viruses that live in close association with our bodies. There is a microbiome associated with our skins, with our mouth and nose, with our ears and eyes, with our respiratory tracts, our urogenital tracts, and with our gut. Over the past few years, there has been increasing interest in the interaction between our microbiome and the cells and tissues of our body. The gut microbiome contains somewhere in excess of $10^{14}$ bacteria, representing over 1000 species (upward of 6000 strains) and contributing 150 times the genetic material of our own genome. ${ }^{85}$ It has become evident that the gut microbiome communicates with our body and that our body in turn communicates with the microbiome. ${ }^{86,87}$ For these reasons, the gut microbiome is often given the importance of an additional organ and, in common with other organs, has its own circadian rhythm. ${ }^{88}$ The intimate relationship of the human host and the bacteria of the microbiome is often referred to as the holobiont, with the holobiome being the total genetic material of the partners.

The gut microbiome of lean and healthy humans (and model organisms) is quite different to that of obese humans and animals. In fact, it is now recognized that a healthy gut microbiome is to a large extent responsible for a healthy individual. Changes in the health status of humans and model organisms are accompanied by changes in the gut microbiome, which can include genus-level, family-level, and even phylum-level fluctuations in the microorganisms that are present, as well as changes in microbial diversity (either increased or decreased diversity). The microbiome shows differences with different metabolic diseases and disorders and there is a microbiome component to such disparate diseases as cardiovascular disease (including heart failure) and neurological disorders (including Parkinson's disease). ${ }^{89-91}$ Thus, it has been recognized that there is a microbiome/gut/brain axis, a microbiome/gut/heart axis, and possibly a microbiome/gut/muscle axis, ${ }^{92}$ a microbiome/gut/lung axis, ${ }^{93}$ and a microbiome/gut/skin axis. ${ }^{94}$ More recently, links between the gut and pain, ${ }^{95}$ the gut and arthritis, and the gut and neutrophils ${ }^{96}$ have been proposed.

The composition of the microbiome is affected by birthing practice (vaginal/cesarean), growth through infancy (breast milk/formula) to adulthood (vegan/meat-based diet), genetics (the HLA-B27 gene may cause gut dysbiosis, leading to spondylarthrosis ${ }^{97}$ ), aging, stress, antibiotics, and diet (including alcohol consumption, prebiotics, probiotics), all of which shape the overall composition of the microbiome. ${ }^{87}$ A changed diet (e.g., high fat, high sugar, plantbased, vegan, etc.) can change the microbiome in the short or long term. ${ }^{90,98}$ A diet high in a diversity of plant products is generally linked with greater species richness in the gut, ${ }^{99}$ whereas a more meat-based diet leads to a replacement of carbohydrate-fermenting bacteria with bile-tolerant bacteria. $^{86}$

Gut microbiota assist in food digestion, change the kilojoule yield of the food, and contribute to vitamin and mineral production and intake, and more efficient energy production from a dysregulated microbiome may be one factor in obesity, ${ }^{90,100}$ due to increased energy harvest from polysaccharides and inhibition of fasting-induced adipose factor and monophosphate-activated protein kinase, both of which influence deposition of body fat. ${ }^{101}$ A western diet results in changes in the microbiome of both humans ${ }^{98}$ and mice, ${ }^{102}$ a trait which is transferable with fecal transplants. ${ }^{90}$ Antibiotics as well as nonantibiotic drugs, including proton pump inhibitors, can disrupt the microbiome and generate long-term effects. ${ }^{86,103,104}$ Metformin and Acarbose, both used to treat type 2 diabetes, have been shown to have positive effects on the microbiome. ${ }^{105-107}$

The main communication pathways between the microbiome and the body are through the immune response, redox signaling, the endocrine system and the enteric/vagus nerve pathway; summarized in Fig. 2. One of the major known effects of the microbiome is the release of short-chain fatty acids (SCFAs), such as butyrate, acetate, and propionate, produced by fermentation of undigested polysaccharides or proteins. SCFAs influence the integrity of the gut mucosa by increasing epithelial integrity and production of mucus and influence the body's energy balance, inflammatory response, and protect against cancer. ${ }^{89,90,108}$ They are potent signaling molecules, affecting a number of G-protein-coupled receptors, resulting in such effects as increased glucagon-like peptide 1, leptin, and peptide YY; increased insulin sensitivity; increased energy expenditure; increased satiety; and protection against irritable bowel disease and cancer (reviewed by Koh, et al. ${ }^{108}$ ). The microbiome also has a role in tryptophan metabolism, producing tryptophan catabolites such as indole and indolepropionic acid (IPA), ${ }^{109}$ which are also anti-inflammatory and influence the kynurenine pathway. ${ }^{110}$ Gut bacteria (especially the lactobacilli) are known to generate ROS, at levels that are able to influence cell signaling and reduce the inflammatory response. ${ }^{111}$ The microbiota in the gut also produce the active forms of polyphenols, by altering the bound state of these molecules in plant foods. ${ }^{112}$

Microbes in the gut produce other metabolites, including neurotransmitters and hormones, which cross the intestinal mucosa, interact with cells and tissues of the body, and contribute to the metabolites that can be detected in the circulation. ${ }^{113}$ These signaling molecules may be identical to those produced by the body or close analogs that the body can recognize and have a role in regulating appetite, weight gain, insulin sensitivity, peripheral lipid storage, and liver and muscle energy balance. Such signaling molecules include catecholamines, serotonin, gamma aminobutyric acid (GABA), dopamine, acetylcholine, $\alpha-\mathrm{MSH}$, norepinephrine, and melatonin, all of which can leave the gut lumen. ${ }^{109,114,115}$ The microbiota also influences the production of metabolites by the enteroendocrine cells. For example, $90 \%$ of the body's serotonin is produced by enteroendocrine cells in the gut, ${ }^{116}$ which has a major influence on mood and cognition. ${ }^{117}$

Communication between the microbiome and the brain (microbiome/gut/brain axis) is also possible through the 

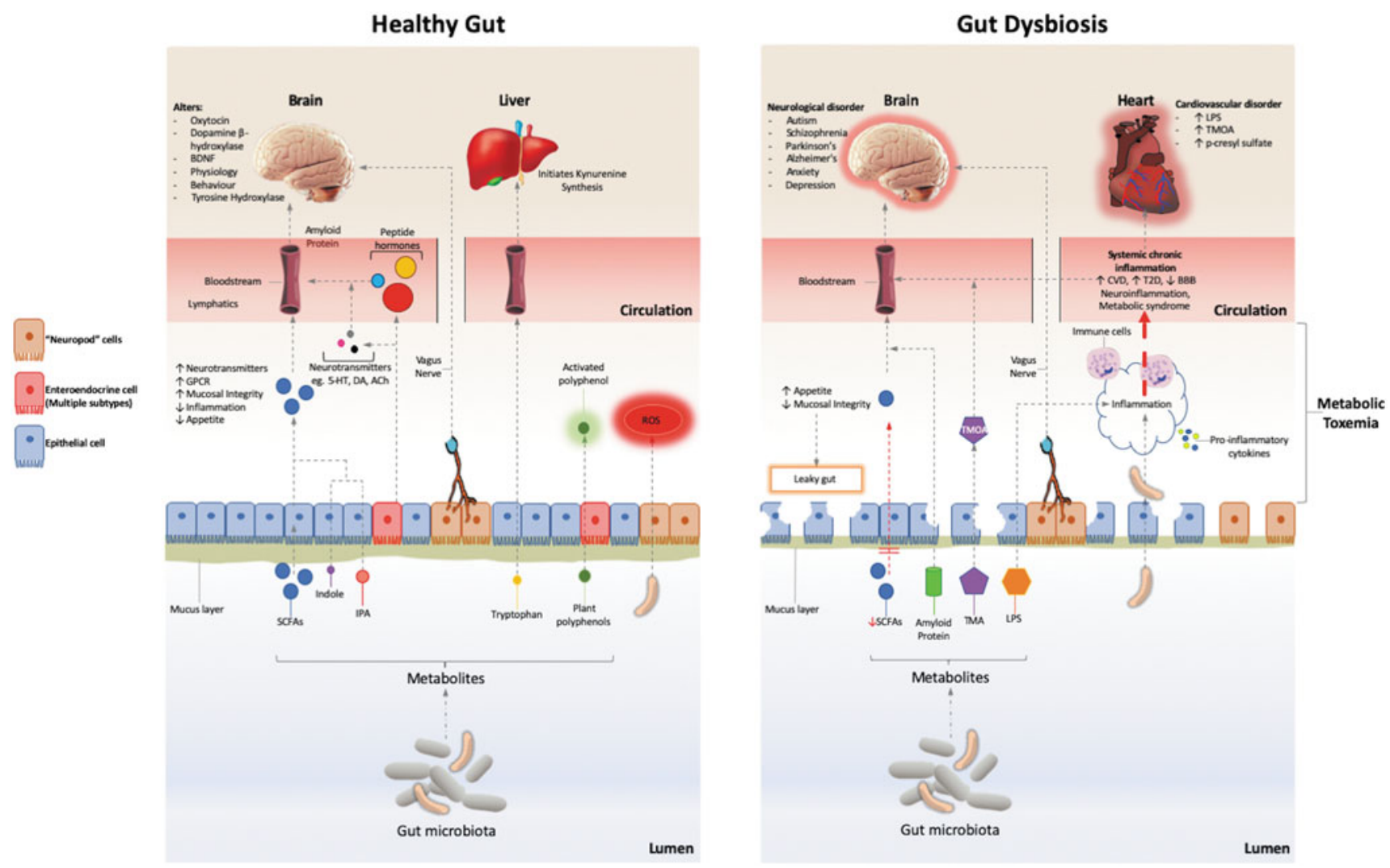

FIG. 2. The main interactions between the microbiome and the body with a healthy and unhealthy microbiome. Bacteria in the microbiota produce SCFA, influence redox signaling, influence tryptophan metabolism, activate plant polyphenols, and produce neurotransmitters, hormones, and peptides. This has the effect of promoting a thick mucus layer, an intact epithelium, and producing numerous downstream metabolomic effects. The microbiome communicates with the body through these metabolites as well as direct communication through the vagus nerve. In dysbiosis, reduced SCFA levels weaken epithelial integrity, increasing efflux of bacterial metabolites, such as proteins and LPS, contributing to an increased inflammatory response and "leaky gut." Production of TMOA and p-cresyl sulfate are correlated with cardiovascular disease. 5-HT, serotonin; ACh, acetyl choline; BBB, blood brain barrier; CVD, cardiovascular disease; DA, dopamine; GPCR, G protein couple receptor; IPA, indolepropionic acid; LPS, lipopolysaccharide; ROS, reactive oxygen species; SCFAs, short chain fatty acids; T2D, type II diabetes; TMA, trimethylamine; TMOA, trimethylamine oxide.

vagus nerve, the direct link between the brain and the enteric nervous system, which communicates directly with the gut lumen and is exposed to microbially produced neurotransmitters. ${ }^{118}$ Recently, enteroendocrine cells (so-called "neuropod" cells) have been shown to synapse with the vagus nerve to transmit signals directly from the gut to the brain in a single synapse. ${ }^{119}$ The vagus nerve can influence gut motility and mucin secretion, both of which will affect the microbiome. ${ }^{113}$ In addition, SCFA have also been shown to directly influence the sympathetic nervous system, through G-protein-coupled receptors. ${ }^{120}$

\section{Microbiome and Human Disease}

A dysregulated microbiome having an effect on host health is known as dysbiosis. This can be caused by stress, aging, antibiotics, hygiene breakdown, and diet (absence of fiber and resistant starches). Dysbiosis will lead to decreased mucosal integrity and the movement of bacteria and microbial products into the portal circulation, the liver, and the systemic circulation (Fig. 2). These products include lactic acid, ammonium ions, endotoxins, bacterial cell wall com- ponents (lipopolysaccharide and peptidoglycan), membrane lipids, DNA, and whole bacterial cells. An altered microbiome can affect lipid metabolism, glucose metabolism, protein turnover, and redox balance as well as increasing biomarkers such as cholesterol, free fatty acids, fibroblast growth factor 21, bilirubin and lactate, ${ }^{121}$ and inflammatory markers such as interleukin 6 (IL-6) and tumor necrosis factor alpha (TNF- $\alpha$ ).

The reduced SCFA production by the microbiome due to dysbiosis leads to decreased mucosal integrity and a thinning of the mucous layer. ${ }^{122}$ The leaking of microbial metabolites, products, or entire microbes from the intestinal lumen into the tissues sets up an inflammatory response, which then further reduces the integrity of the gut, leading to systemic chronic inflammation. ${ }^{123}$ Cytokines produced by the mucosal immune system can be released into the gut lumen and so in turn affect the microbiome. The inflammatory response associated with dysbiosis is correlated with obesity, ulcerative colitis, irritable bowel disease and Crohn's disease, metabolic syndrome, type 2 diabetes, cardiovascular disease, and cancer. ${ }^{91,101,108,122,124-127}$ Inflammation will also directly affect the central nervous 
system, through the vagus nerve, the sympathetic and parasympathetic nervous systems, and the neuroimmune system. ${ }^{128}$ The systemic and neuroinflammation associated with dysbiosis has been associated with cardiovascular disease (including hypertension, atherosclerosis, and heart failure), the mild cognitive impairment of aging, and a number of intractable neurodegenerative diseases and neurological disorders, including multiple sclerosis, Alzheimer's disease (gut and oral microbiome), Huntington's disease, autism spectrum disorder, schizophrenia, anxiety, and depression in both humans and laboratory rodents. ${ }^{129-134}$

Dysbiosis also disrupts tryptophan metabolism, shifting the balance of serotonin and kynurenine pathways. ${ }^{135}$ A disturbed kynurenine pathway has been linked to Parkinson's, ${ }^{136}$ cardiovascular disease, ${ }^{137}$ multiple sclerosis, amyotrophic lateral sclerosis (ALS), and other neurological diseases. ${ }^{138}$

There is a particularly strong link between the microbiome and Parkinson's disease, where the constipation suffered by a majority of Parkinson's disease sufferers ${ }^{139}$ is linked to $\alpha$-synuclein accumulation in the enteric nervous system, increased intestinal permeability (leaky gut), and local inflammation (increased proinflammatory cytokines), which can occur years before the neural symptoms of Parkinson's disease become apparent. ${ }^{140}$ Interestingly, both rats and transgenic $C$. elegans models of Parkinson's disease show increased aggregation of $\alpha$-synuclein as well as increased neural inflammation when exposed to bacteria that produce "curli", a bacterial amyloid protein. ${ }^{141}$

The intestinal microbiome appears to have a causal role in the development and progression of atherosclerosis. In addition to obesity being a major risk factor for cardiovascular disease, dysbiosis results in the production of trimethylamine oxide produced in the liver from trimethylamine released by the gut microbiome. ${ }^{142}$ Trimethylamine oxide is a predictor of cardiovascular disease, although the causative link has yet to be established. ${ }^{143,144}$ Atherosclerotic cardiovascular disease also appears to be correlated with distinctive differences in the microbiome, including increased abundance of Enterobacteriaceae and Streptococcus spp. ${ }^{145}$ Dysbiosis has been linked with hypertension, atherosclerosis, arterial thrombosis, altered cholesterol and lipid profile, and heart failure ${ }^{146}$ and the gut microbiome has been shown to have a direct role in regulating blood pressure ${ }^{144}$ and blood lipids ${ }^{147}$ in rodents. Additionally, there is also a major link between the oral microbiome and cardiovascular disease, with Porphyromonas gingivalis (the causative agent in oral gingivitis) linked to atherosclerosis and found in the atherosclerotic plaques. ${ }^{148}$

It has also become apparent that dysbiosis is associated with chronic pain syndromes, including visceral pain, ${ }^{149}$ migraine (gut and oral microbiomes), ${ }^{150}$ chronic prostatitis and pelvic pain (gut and urogenital microbiomes), ${ }_{151}$ and autoimmune diseases such as rheumatoid arthritis. ${ }^{152}$

\section{PBM Alters the Microbiome}

We have shown in a previous study ${ }^{153}$ that PBM, delivered as low-level laser, to the abdomen of healthy mice can produce a significant change in the gut microbiome. PBM significantly altered the microbial diversity of the microbiome, an effect most pronounced in mice treated three times per week with NIR light $(808 \mathrm{~nm})$, but not apparent with a single treatment with red light. PBM also produced a 10,000 -fold increase in the proportion of the beneficial bacterium Allobaculum in the microbiota of mice after 14 days of treatment with NIR light but not with red light (Fig. 3).

This study has recently been repeated (unpublished) with larger numbers of mice in the experimental groups (10 per treatment group). The wavelength was again shown to be an important parameter, with NIR wavelengths showing a more pronounced effect than red light, and the proportion of bacteria associated with a healthy microbiome in mice generally increased while the proportion of bacteria associated with a dysregulated microbiome generally decreased. Blivet and colleagues have also hypothesized that the microbiome (in mice) is important for the treatment of Alzheimer's disease with PBM $^{154}$ and have shown significant changes in the microbiome of mice injected with $\beta$-amyloid after treatment with a combination of PBM wavelengths and a static magnetic field (personal communication and ${ }^{155}$ ). Recent preliminary work from our laboratory (unpublished) has also indicated that changes in the human (quasimetabolic syndrome) microbiome occur after treatment with PBM, including increases in Akkermansia muciniphila, Bifidobacterium sp., and Faecalibacterium sp., all recognized as correlated with a healthy microbiome, ${ }^{156-158}$ and decreases in the Firmicutes:Bacteroides ratio, proposed as an indicator of gut health. ${ }^{159,160}$

UV therapy of skin has been shown to affect the skin microbiome by altering barrier function, leading to microbial-specific skin-resident memory $\mathrm{T}$ cells, disrupting the healthy balance between skin microbiome and skin immune cells, and resulting in chronic inflammation and diseased skin. ${ }^{161}$ On the other hand, UV irradiation of blood has been used for infections, autoimmune diseases, and some metabolic disorders. ${ }^{162,163}$ The mechanisms of action are still uncertain despite many years of investigation.

\section{Mechanisms of Action of PBM on the Microbiome}

Because the whole field of "photobiomics" is so new, the discussion of possible mechanisms of action must remain highly speculative. They key question that must be addressed by further research is whether the light is primarily absorbed by the microbial cells themselves that make up the human microbiome, by the host cells that surround the microbes (or indeed cells that are distant from them), or by a combination of both microbes and host cells. The known chromophores for PBM, such as CCO, opsins, and flavoproteins, have mainly been investigated in mammalian cells. Nevertheless, there is a considerable body of work, largely emanating from Tiina Karu in Russia that a diverse range of bacterial species (both Gram-positives and Gram-negatives) and fungal (including yeast) cells do indeed respond to PBM. ${ }^{164,165}$ This response was mostly shown by increased proliferation of the microbial cells, but considering the biphasic nature of the PBM dose/response curve, ${ }^{166,167}$ at higher doses, inhibition was also observed. Similarly, de Sousa and colleagues ${ }^{168}$ have also shown that PBM inhibits the in vitro growth of bacteria that infect skin ulcers.

Alternatively, the alteration of the microbiome that was observed in the mouse experiments may be due to a 


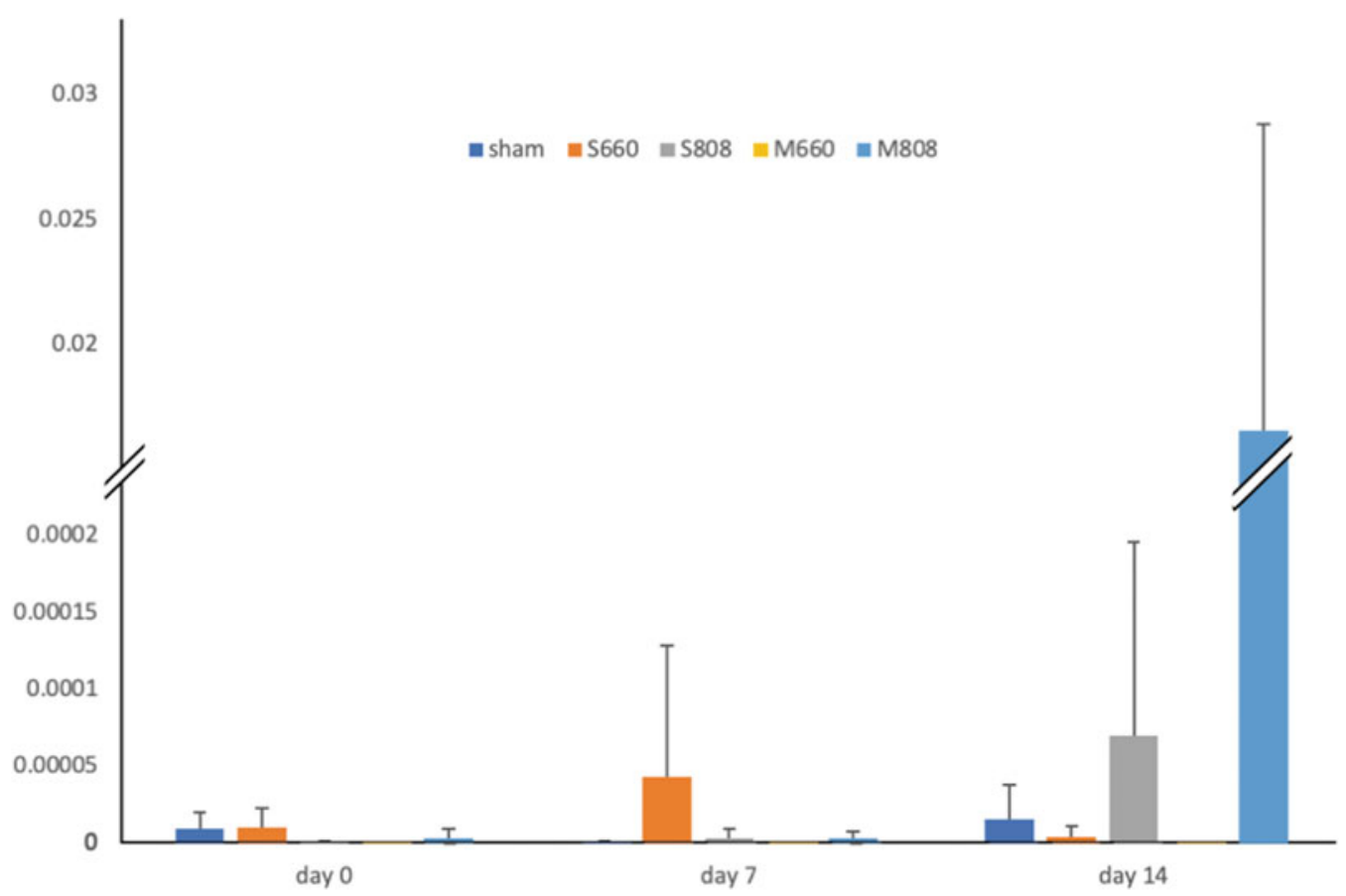

FIG. 3. Change in the proportion of Allobaculum sp. in the total microbiota after PBM treatment with red and infrared laser. M, multiple (three times per week/2 weeks) dose of PBM; S, single dose of PBM. (adapted from Bicknell et al. ${ }^{153}$ ).

secondary effect of PBM, affecting the mouse inflammatory response, and in turn affecting the gut microbiota. This is entirely feasible, given the intimate relationship between the microbiome (healthy and dysbiosis) and the inflammatory response. It is hypothesized that this effect may be due to the well-known anti-inflammatory and redox signaling effect of PBM. ${ }^{60,80}$ PBM can reduce proinflammatory cytokines, such as IL-6, TNF- $\alpha$, IFN- $\gamma,{ }^{169}$ and change the activity of macrophages and neutrophils. ${ }^{80}$ Importantly PBM can change the "polarization state" of cells from macrophage lineage $^{170}$ proinflammatory M1 to anti-inflammatory M2 phenotype.

In a series of experiments on Parkinson's disease, Stone, Johnstone, Mitrofanis and colleagues have shown that neuroprotection against Parkinsonian MPTP insult (in mice) can be achieved with PBM delivered to areas of the body remote from the brain. ${ }^{36,171-174}$ This abscopal effect of PBM is postulated to be due to immune cells, stem cells, or a circulating (unidentified) mediator. The possibility exists that this mediator is linked to changes in the microbiome.

\section{Potential Applications to Human Disease}

It is entirely possible that some of the beneficial effects of PBM on systemic conditions and metabolic disorders that have historically been observed have been due to effects on the gut microbiome rather than the local tissue and this possibility has gone unrecognized until now. The lack of convincing scientific mechanistic evidence obtained so far, for the well-established abscopal effects of PBM, for instance, those seen in animal models of Parkinson's disease and in some cardiovascular disorders, suggests there may be room for this alternative explanation.
PBM may serve as a way to beneficially change the microbiome for a number of different inflammatory and neurological diseases (such as cardiovascular and Parkinson's diseases). The obvious approaches to try to improve the microbiome in humans such as diet, probiotics, and fecal transplants have had some success, but these treatments do not amount to a complete solution for the entire problem. Fecal transplants are currently being used for Clostridium difficile infection, irritable bowel disease, ulcerative colitis, ${ }^{175}$ and are also being considered for some nonintestinal metabolic diseases. Fecal transplants have been shown (in mice) to suppress neuroinflammation and TNF- $\alpha$ signaling, and to reduce the symptoms of Parkinson's disease and dysbiosis. ${ }^{176}$ PBM has the potential to act as an adjunct treatment (along with modifications of diet and exercise) to rebalance the microbiome. A healthy microbiome would balance SCFA production, serotonin/kynurenine pathways, trimethylamine metabolism, and dopamine and neurotransmitter production, which, in turn may affect the outcome of some of the most difficult-to-treat diseases, including Parkinson's disease, multiple sclerosis, amyotrophic lateral sclerosis, attention-deficit/hyperactivity disorder, and autism spectrum disorder.

\section{Conclusions}

While metabolomics specifically excludes the microbiome, the two are inexorably linked; the microbiome directly affects the body and the body also influences the microbiome. The combination of the metabolome and the microbiome (the holobiont or holobiome) appears to be able to be changed by light, specifically by PBM. In light of the evidence that PBM can influence the microbiome and the known effect of PBM on cytokines, transcription factors, 
and the metabolome we introduce the term "photobiomics" to represent the combined effects of PBM on metabolomic factors, the microbiome, and the interaction between the two. Photobiomics most probably has a wider application than simply PBM. As is now generally understood, light has an effect on a wide range of living organisms in multiple biological kingdoms. ${ }^{1}$ Light in general may affect the microbiome as a downstream effect. The microbiome has been increasingly shown over the last decade to be a powerful influence on a range of diseases and to be very important in the maintenance of optimum health. The ability of PBM to influence the microbiome (if proven to be applicable to humans) will allow an additional therapeutic route to target multiple diseases, including cardiovascular disease and Parkinson's disease, many of which have thus far eluded effective treatment approaches.

\section{Author Disclosure Statement}

Dr. Bicknell is an agent for Spectro Analytic Irradia AB. Dr. Hamblin is on the following Scientific Advisory Boards: Transdermal Cap, Inc., Cleveland, OH; BeWell Global, Inc., Wan Chai, Hong Kong; Hologenix, Inc., Santa Monica, CA; LumiThera, Inc., Poulsbo, WA; Vielight, Toronto, Canada; Bright Photomedicine, Sao Paulo, Brazil; Quantum Dynamics LLC, Cambridge, MA; Global Photon, Inc., Bee Cave, TX; Medical Coherence, Boston, MA; NeuroThera, Newark, DE; JOOVV, Inc., Minneapolis-St. Paul, MN; AIRx Medical, Pleasanton, CA; FIR Industries, Inc., Ramsey, NJ; UVLRx Therapeutics, Oldsmar, FL; Ultralux UV, Inc., Lansing, MI; Illumiheal \& PetThera, Shoreline, WA; and MB Lasertherapy, Houston, TX. Dr. Hamblin has been a consultant for Lexington Int, Boca Raton, FL; USHIO Corp, Japan; Merck KGaA, Darmstadt, Germany; Philips Electronics Nederland B.V. Johnson \& Johnson, Inc., Philadelphia, PA; and Sanofi-Aventis Deutschland GmbH, Frankfurt am Main, Germany. Dr. Hamblin is a stockholder in Global Photon, Inc., Bee Cave, TX; and Mitonix, Newark, DE.

\section{Funding Information}

There was no funding provided for this article.

\section{References}

1. Hamblin MR, Huang YY, Heiskanen V. Non-mammalian hosts and photobiomodulation: do all life-forms respond to light? Photochem Photobiol 2018;95:126-139.

2. Grzybowski A, Pietrzak K. From patient to discoverer-Niels Ryberg Finsen (1860-1904) — the founder of phototherapy in dermatology. Clin Dermatol 2012;30:451-455.

3. Rutten S, Vriend C, van den Heuvel OA, Smit JH, Berendse HW, van der Werf YD. Bright light therapy in Parkinson's disease: an overview of the background and evidence. Parkinsons Dis 2012;2012:767105.

4. Oldham MA, Ciraulo DA. Bright light therapy for depression: a review of its effects on chronobiology and the autonomic nervous system. Chronobiol Int 2014;31:305-319.

5. Willis GL, Boda J, Freelance CB. Polychromatic light exposure as a therapeutic in the treatment and management of Parkinson's disease: a controlled exploratory trial. Front Neurol 2018;9:741.

6. Kent A, Abel-Latif M, Cochrane T, et al. A pilot randomised clinical trial of $670 \mathrm{~nm}$ red light for reducing reti- nopathy of prematurity. J Paediatr Child Health 2018;54: 27-28.

7. Geneva II. Photobiomodulation for the treatment of retinal diseases: a review. Int J Ophthalmol 2016;9:145-152.

8. Natoli R, Valter K, Barbosa M, et al. $670 \mathrm{~nm}$ photobiomodulation as a novel protection against retinopathy of prematurity: evidence from oxygen induced retinopathy models. PLoS One 2013;8:e72135.

9. Ivandic BT, Ivandic T. Low-level laser therapy improves vision in patients with age-related macular degeneration. Photomed Laser Surg 2008;26:241-245.

10. Vandewalle G, Schwartz S, Grandjean D, et al. Spectral quality of light modulates emotional brain responses in humans. Proc Natl Acad Sci U S A 2010;107:1954919554.

11. Noseda R, Lee AJ, Nir R-R, et al. Neural mechanism for hypothalamic-mediated autonomic responses to light during migraine. Proc Natl Acad Sci U S A 2017;114: E5683-E5692.

12. Vandewalle G, Maquet P, Dijk DJ. Light as a modulator of cognitive brain function. Trends Cogn Sci 2009;13: 429-438.

13. Tsimakouridze EV, Alibhai FJ, Martino TA. Therapeutic applications of circadian rhythms for the cardiovascular system. Front Pharmacol 2015;6:77.

14. Beauchemin KM, Hays P. Dying in the dark: sunshine, gender and outcomes in myocardial infarction. J R Soc Med 1998;91:352-354.

15. Thaiss CA, Levy M, Korem T, et al. Microbiota diurnal rhythmicity programs host transcriptome oscillations. Cell 2016;167:1495-1510.e1412.

16. Cui M, Xiao H, Luo D, et al. Circadian rhythm shapes the gut microbiota affecting host radiosensitivity. Int $\mathrm{J}$ Mol Sci 2016;17:1786.

17. Liang X, FitzGerald GA. Timing the microbes: the circadian rhythm of the gut microbiome. J Biol Rhythms 2017;32:505-515.

18. Deaver JA, Eum SY, Toborek M. Circadian disruption changes gut microbiome taxa and functional gene composition. Front Microbiol 2018;9:737.

19. Gubatan J, Moss AC. Vitamin D in inflammatory bowel disease: more than just a supplement. Curr Opin Gastroenterol 218;34:217-225.

20. Nakamura K, Sakuragi N, Takakuwa A, Ayabe T. Paneth cell $\alpha$-defensins and enteric microbiota in health and disease. Biosci Microbiota Food Health 2016;35: 57-67.

21. Ooi JH, Li Y, Rogers CJ, Cantorna MT. Vitamin D regulates the gut microbiome and protects mice from dextran sodium sulfate-induced colitis. J Nutr 2013;143:16791686.

22. Luthold RV, Fernandes GR, Franco-de-Moraes AC, Folchetti LGD, Ferreira SRG. Gut microbiota interactions with the immunomodulatory role of vitamin $\mathrm{D}$ in normal individuals. Metabolism 2017;69:76-86.

23. Meckel K, Li YC, Lim J, et al. Serum 25-hydroxyvitamin $\mathrm{D}$ concentration is inversely associated with mucosal inflammation in patients with ulcerative colitis. Am J Clin Nutr 2016;104:113-120.

24. Disanto G, Chaplin G, Morahan JM, et al. Month of birth, vitamin $\mathrm{D}$ and risk of immune-mediated disease: a case control study. BMC Med 2012;10:69.

25. Singh MM, Mullin GE. Diet, environmental chemicals, and the gut microbiome. In: Integrative Environmental 
Medicine. A Cohen, FS vom Saal (eds.). New York, NY: Oxford University Press, 2017: pp.115-140.

26. Gooley JJ, Chamberlain K, Smith KA, et al. Exposure to room light before bedtime suppresses melatonin onset and shortens melatonin duration in humans. J Clin Endocrinol Metab 2011;96:E463-E472.

27. Figueiro MG, Plitnick B, Rea MS. Light modulates leptin and ghrelin in sleep-restricted adults. Int $\mathrm{J}$ Endocrinol 2012;2012:6.

28. Basha AA, Mathangi D, Shyamala R. Fluorescent light induced oxidative damage in Wistar strain albino rat: possible protective effect of LED light induced photobiomodulation. Indian J Physiol Pharmacol 2018;62:187194.

29. Boswell M, Lu Y, Boswell W, et al. Fluorescent light incites a conserved immune and inflammatory genetic response within vertebrate organs (Danio rerio, Oryzias latipes and Mus musculus). Genes 2019;10:271.

30. Mester E, Ludany G, Selyei M, Szende B, Total GJ. The simulating effect of low power laser rays on biological systems. Laser Rev 1968;1:3.

31. Hamblin MR. Photobiomodulation or low-level laser therapy. J Biophotonics 2016;9:1122-1124.

32. de Freitas LF, Hamblin MR. Proposed mechanisms of photobiomodulation or low-level light therapy. IEEE J Sel Top Quantum Electron 2016;22:pii:7000417.

33. Lima PL, Pereira CV, Nissanka N, et al. Photobiomodulation enhancement of cell proliferation at $660 \mathrm{~nm}$ does not require cytochrome c oxidase. J Photochem Photobiol B 2019;194:71-75.

34. Wang Y, Huang YY, Wang Y, Lyu P, Hamblin MR. Photobiomodulation (blue and green light) encourages osteoblastic-differentiation of human adipose-derived stem cells: role of intracellular calcium and light-gated ion channels. Sci Rep 2016;6:33719.

35. Khan I, Arany P. Biophysical approaches for oral wound healing: emphasis on photobiomodulation. Adv Wound Care 2015;4:724-737.

36. Ganeshan V, Skladnev NV, Kim JY, Mitrofanis J, Stone J, Johnstone DM. Pre-conditioning with remote photobiomodulation modulates the brain transcriptome and protects against MPTP insult in mice. Neuroscience 2019; 400:85-97.

37. Ondrusova K, Fatehi M, Barr A, et al. Subcutaneous white adipocytes express a light sensitive signaling pathway mediated via a melanopsin/TRPC channel axis. Sci Rep 2017;7:16332.

38. Nissilä JS, Mänttäri SK, Särkioja TT, et al. The distribution of melanopsin (OPN4) protein in the human brain. Chronobiol Int 2017;34:37-44.

39. Sikka G, Hussmann GP, Pandey D, et al. Melanopsin mediates light-dependent relaxation in blood vessels. Proc Natl Acad Sci U S A 2014;111:17977-17982.

40. Emanuel AJ, Do MTH. Melanopsin tristability for sustained and broadband phototransduction. Neuron 2015;85: 1043-1055.

41. Flyktman A, Mänttäri S, Nissilä J, Timonen M, Saarela S. Transcranial light affects plasma monoamine levels and expression of brain encephalopsin in the mouse. J Exp Biol 2015;218:1521-1526.

42. Liebert A, Bicknell B, Adams R. Protein conformational modulation by photons: a mechanism for laser treatment effects. Med Hypotheses 2014;82:275-281.
43. Rodríguez-Santana E, Santana-Blank L. Emerging evidence on the crystalline water-light interface in ophthalmology and therapeutic implications in photobiomodulation: first communication. Photomed Laser Surg 2014;32:240-242.

44. Santana-Blank L, Rodríguez-Santana E. The interaction of light with nanoscopic layers of water may be essential to the future of photobiomodulation. Photomed Laser Surg 2010;28:S-173-S-174.

45. Chow R, David M, Armati P. 830nm laser irradiation induces varicosity formation, reduces mitochondrial membrane potential and blocks fast axonal flow in small and medium diameter rat dorsal root dorsal root ganglion: implications for the analgesic effects of $830 \mathrm{~nm}$ laser. J Peripher Nerv Syst 2007;12:28-39.

46. Holanda VM, Chavantes MC, Silva DFT, et al. Photobiomodulation of the dorsal root ganglion for the treatment of low back pain: a pilot study. Lasers Surg Med 2016;48:653-659.

47. Holanda VM, Chavantes MC, Wu X, Anders JJ. The mechanistic basis for photobiomodulation therapy of neuropathic pain by near infrared laser light. Lasers Surg Med 2017;49:516-524.

48. Liebert AD, Chow RT, Bicknell BT, Varigos E. Neuroprotective effects against POCD by photobiomodulation: evidence from assembly/disassembly of the cytoskeleton. J Exp Neurosci 2016;10:1.

49. Chen M-Y, Shimada K, Fujita K, Ishill J, Hirata T, Fujisawa $H$. Neurite elongation from cultured dorsal root ganglion cells is inhibited by $\mathrm{Ga}-\mathrm{Al}$-As diode laser irradiation. Lasers Life Sci 1993;5:237-242.

50. Ricci R, Pazos MC, Borges RE, Pacheco-Soares C. Biomodulation with low-level laser radiation induces changes in endothelial cell actin filaments and cytoskeletal organization. J Photochem Photobiol B 2009;95:6-8.

51. Huang C, Qian SL, Sun LY, Cheng B. Light-emitting diode irradiation $(640 \mathrm{~nm})$ regulates keratinocyte migration and cytoskeletal reorganization via hypoxiainducible factor-1alpha. Photomed Laser Surg 2016;34: 313-320.

52. Oliveira DA, De Oliveira RF, Magini M, Zangaro RA, Soares CP. Assessment of cytoskeleton and endoplasmic reticulum of fibroblast cells subjected to low-level laser therapy and low-intensity pulsed ultrasound. Photomed Laser Surg 2009;27:461-466.

53. Wang Y, Huang YY, Wang Y, Lyu P, Hamblin MR. Red $(660 \mathrm{~nm})$ or near-infrared $(810 \mathrm{~nm})$ photobiomodulation stimulates, while blue $(415 \mathrm{~nm})$, green $(540 \mathrm{~nm})$ light inhibits proliferation in human adipose-derived stem cells. Sci Rep 2017;7:7781.

54. Wang Y, Huang YY, Wang Y, Lyu P, Hamblin MR. Photobiomodulation of human adipose-derived stem cells using $810 \mathrm{~nm}$ and $980 \mathrm{~nm}$ lasers operates via different mechanisms of action. Biochim Biophys Acta Gen Subj 2017;1861:441-449.

55. Wu ZH, Zhou Y, Chen JY, Zhou LW. Mitochondrial signaling for histamine releases in laser-irradiated RBL2H3 mast cells. Lasers Surg Med 2010;42:503-509.

56. Zomorrodi R, Loheswaran G, Pushparaj A, Lim L. Pulsed near infrared transcranial and intranasal photobiomodulation significantly modulates neural oscillations: a pilot exploratory study. Sci Rep 2019;9:6309.

57. Zomorrodi R, Loheswaran G, Pushparaj A, Lim L. Modulation of neural oscillation power spectral density with 
transcranial photobiomodulation. Brain Stimul 2019;12: 457-458.

58. Ho M, Martin P, Yee M, et al. Increased functional connectivity in default mode network associated with application of transcranial, light-emitting diodes to treat chronic aphasia: case series. J Int Neuropsychol Soc 2016; 22:229.

59. Ferraresi C, Huang YY, Hamblin MR. Photobiomodulation in human muscle tissue: an advantage in sports performance? J Biophotonics 2016;9:1273-1299.

60. Hamblin MR. Mechanisms and mitochondrial redox signaling in photobiomodulation. Photochem Photobiol 2018;94:199-212.

61. Liebert A. Emerging applications of photobiomodulation therapy: the interaction between metabolomics and the microbiome. Photomed Laser Surg 2018;36:515-517.

62. Kim B, Brandli A, Mitrofanis J, Stone J, Purushothuman S, Johnstone DM. Remote tissue conditioning - an emerging approach for inducing body-wide protection against diseases of ageing. Ageing Res Rev 2017;37:69-78.

63. Johnstone DM, Moro C, Stone J, Benabid AL, Mitrofanis J. Turning on lights to stop neurodegeneration: the potential of near infrared light therapy in Alzheimer's and Parkinson's disease. Front Neurosci 2016;9:500.

64. Durieux J, Wolff S, Dillin A. The cell-non-autonomous nature of electron transport chain-mediated longevity. Cell 2011;144:79-91.

65. Taylor RC, Berendzen KM, Dillin A. Systemic stress signalling: understanding the cell non-autonomous control of proteostasis. Nat Rev Mol Cell Biol 2014;15:211217.

66. Yin K, Zhu R, Wang S, Zhao RC. Low-level laser effect on proliferation, migration, and antiapoptosis of mesenchymal stem cells. Stem Cells Dev 2017;26:762-775.

67. Wang Y, Huang Y-Y, Wang Y, Lyu P, Hamblin MR. Red $(660 \mathrm{~nm})$ or near-infrared $(810 \mathrm{~nm})$ photobiomodulation stimulates, while blue $(415 \mathrm{~nm})$, green $(540 \mathrm{~nm})$ light inhibits proliferation in human adipose-derived stem cells. Sci Rep 2017;7:7781.

68. Fekrazad R, Asefi S, Allahdadi M, Kalhori KA. Effect of photobiomodulation on mesenchymal stem cells. Photomed Laser Surg 2016;34:533-542.

69. Abrahamse H. Regenerative medicine, stem cells, and low-level laser therapy: future directives. Photomed Laser Surg 2012;30:681-682.

70. Oron U, Yaakobi T, Oron A, et al. Low-energy laser irradiation reduces formation of scar tissue after myocardial infarction in rats and dogs. Circulation 2001;103:296-301.

71. Ad N, Oron U. Impact of low level laser irradiation on infarct size in the rat following myocardial infarction. Int $\mathbf{J}$ Cardiol 2001;80:109-116.

72. Tuby H, Maltz L, Oron U. Induction of autologous mesenchymal stem cells in the bone marrow by low-level laser therapy has profound beneficial effects on the infarcted rat heart. Lasers Surg Med 2011;43:401-409.

73. Farfara D, Tuby H, Trudler D, et al. Low-level laser therapy ameliorates disease progression in a mouse model of Alzheimer's disease. J Mol Neurosci 2015;55:430-436.

74. Oron A, Oron U. Low-level laser therapy to the bone marrow ameliorates neurodegenerative disease progression in a mouse model of Alzheimer's disease: a minireview. Photomed Laser Surg 2016;34:627-630.

75. Pistollato F, Sumalla Cano S, Elio I, Masias Vergara M, Giampieri F, Battino M. Role of gut microbiota and nu- trients in amyloid formation and pathogenesis of Alzheimer disease. Nutr Rev 2016;74:624-634.

76. Jiang $\mathrm{C}$, Li G, Huang $\mathrm{P}$, Liu Z, Zhao B. The gut microbiota and Alzheimer's disease. J Alzheimers Dis 2017;58: $1-15$.

77. Derkinderen P, Rouaud T, Lebouvier T, Bruley des Varannes S, Neunlist M, De Giorgio R. Parkinson disease: the enteric nervous system spills its guts. Neurology 2011;77: 1761-1767.

78. Klingelhoefer L, Reichmann $\mathrm{H}$. The gut and nonmotor symptoms in Parkinson's disease. Int Rev Neurobiol 2017; 134:787-809.

79. Klingelhoefer L, Reichmann H. Pathogenesis of Parkinson disease-the gut-brain axis and environmental factors. Nat Rev Neurol 2015;11:625-636.

80. Hamblin MR. Mechanisms and applications of the antiinflammatory effects of photobiomodulation. AIMS Biophys 2017;4:337-361.

81. Muili KA, Gopalakrishnan S, Meyer SL, Eells JT, Lyons J-A. Amelioration of experimental autoimmune encephalomyelitis in C57BL/6 mice by photobiomodulation induced by $670 \mathrm{~nm}$ light. PLoS One 2012;7:e30655.

82. Bagheri M, Amini A, Abdollahifar MA, et al. Effects of photobiomodulation on degranulation and number of mast cells and wound strength in skin wound healing of streptozotocin-induced diabetic rats. Photomed Laser Surg 2018;36:415-423.

83. Khuman J, Zhang J, Park J, Carroll JD, Donahue C, Whalen MJ. Low-level laser light therapy improves cognitive deficits and inhibits microglial activation after controlled cortical impact in mice. J Neurotrauma 2012; 29:408-417.

84. Song JW, Li K, Liang ZW, et al. Low-level laser facilitates alternatively activated macrophage/microglia polarization and promotes functional recovery after crush spinal cord injury in rats. Sci Rep 2017;7:620.

85. Qin J, Li R, Raes J, et al. A human gut microbial gene catalogue established by metagenomic sequencing. Nature 2010;464:59-65.

86. Jandhyala S, Talukdar R, Subramanyam C, Vuyyuru H, Sasikala M, Reddy D. Role of the normal gut microbiota. World J Gastroenterol 2016;21:8787-8803.

87. Sekirov I, Russell SL, Antunes LCM, Finlay BB. Gut microbiota in health and disease. Physiol Rev 2010;90: 859-904.

88. Leone V, Gibbons SM, Martinez K, et al. Effects of diurnal variation of gut microbes and high-fat feeding on host circadian clock function and metabolism. Cell Host Microbe 2015;17:681-689.

89. Kau AL, Ahern PP, Griffin NW, Goodman AL, Gordon JI. Human nutrition, the gut microbiome, and immune system: envisioning the future. Nature 2011;474:327.

90. Tilg H, Kaser A. Gut microbiome, obesity, and metabolic dysfunction. J Clin Invest 2011;121:2126-2132.

91. Tang WW, Kitai T, Hazen SL. Gut microbiota in cardiovascular health and disease. Circ Res 2017;120:11831196.

92. Grosicki GJ, Fielding RA, Lustgarten MS. Gut microbiota contribute to age-related changes in skeletal muscle size, composition, and function: biological basis for a gutmuscle axis. Calcif Tissue Int $2018 ; 102: 433-442$.

93. Marsland BJ, Trompette A, Gollwitzer ES. The gut-lung axis in respiratory disease. Ann Am Thorac Soc 2015;12: S150-S156. 
94. Salem I, Ramser A, Isham N, Ghannoum MA. The gut microbiome as a major regulator of the gut-skin axis. Front Microbiol 2018;9:1459.

95. Luczynski P, Tramullas M, Viola M, et al. Microbiota regulates visceral pain in the mouse. eLife 2017;2017: e25887.

96. Zhang D, Chen G, Manwani D, et al. Neutrophil ageing is regulated by the microbiome. Nature 2015;525:528-532.

97. Sibley CH. Autoinflammation and HLA-B27: beyond antigen presentation. Ocul Immunol Inflamm 2016;24: 460-469.

98. Lozupone CA, Stombaugh JI, Gordon JI, Jansson JK, Knight R. Diversity, stability and resilience of the human gut microbiota. Nature 2012;489:220.

99. Heiman ML, Greenway FL. A healthy gastrointestinal microbiome is dependent on dietary diversity. Mol Metab 2016;5:317-320.

100. Turnbaugh PJ, Gordon JI. The core gut microbiome, energy balance and obesity. J Physiol 2009;587:4153-4158.

101. Boulangé CL, Neves AL, Chilloux J, Nicholson JK, Dumas M-E. Impact of the gut microbiota on inflammation, obesity, and metabolic disease. Genome Med 2016;8:42.

102. Raza GS, Putaala H, Hibberd AA, et al. Polydextrose changes the gut microbiome and attenuates fasting triglyceride and cholesterol levels in Western diet fed mice. Sci Rep 2017;7:5294.

103. Maier L, Pruteanu M, Kuhn M, et al. Extensive impact of non-antibiotic drugs on human gut bacteria. Nature 2018; 555:623-628.

104. Imhann F, Bonder MJ, Vila AV, et al. Proton pump inhibitors affect the gut microbiome. Gut 2016;65:740-748.

105. Forslund K, Hildebrand F, Nielsen T, et al. Disentangling type 2 diabetes and metformin treatment signatures in the human gut microbiota. Nature 2015;528:262-266.

106. Wu H, Esteve E, Tremaroli V, et al. Metformin alters the gut microbiome of individuals with treatment-naive type 2 diabetes, contributing to the therapeutic effects of the drug. Nat Med 2017;23:850-858.

107. Baxter NT, Lesniak NA, Sinani H, Schloss PD, Koropatkin NM. The glucoamylase inhibitor acarbose has a diet-dependent and reversible effect on the murine gut microbiome. mSphere 2019;4:e00528-18.

108. Koh A, De Vadder F, Kovatcheva-Datchary P, Bäckhed F. From dietary fiber to host physiology: short-chain fatty acids as key bacterial metabolites. Cell 2016;165:13321345.

109. Roager HM, Licht TR. Microbial tryptophan catabolites in health and disease. Nat Commun 2018;9:3294.

110. Kennedy PJ, Cryan JF, Dinan TG, Clarke G. Kynurenine pathway metabolism and the microbiota-gut-brain axis. Neuropharmacology 2017;112:399-412.

111. Jones RM, Neish AS. Redox signaling mediated by the gut microbiota. Free Radic Biol Med 2017;105:41-47.

112. Fu J, Bonder M, Cenit M, et al. The gut microbiome contributes to a substantial proportion of the variation in blood lipids. Circ Res 2015;117:817-824.

113. Mayer EA, Tillisch K, Gupta A. Gut/brain axis and the microbiota. J Clin Invest 2015;125:926-938.

114. Anderson G, Vaillancourt C, Maes M, Reiter RJ. Breastfeeding and the gut-brain axis: is there a role for melatonin? Biomol Concepts 2017;8:185-195.

115. Tetel MJ, de Vries GJ, Melcangi RC, Panzica G, O'Mahony SM. Steroids, stress, and the gut microbiomebrain axis. J Neuroendocrinol 2018;30:e12548.
116. Gershon MD, Tack J. The serotonin signaling system: from basic understanding to drug development for functional GI disorders. Gastroenterology 2007;132:397-414.

117. Jenkins T, Nguyen J, Polglaze K, Bertrand P. Influence of tryptophan and serotonin on mood and cognition with a possible role of the gut-brain axis. Nutrients 2016;8:56.

118. Bravo JA, Forsythe P, Chew MV, et al. Ingestion of Lactobacillus strain regulates emotional behavior and central GABA receptor expression in a mouse via the vagus nerve. Proc Natl Acad Sci U S A 2011;108:1605016055.

119. Kaelberer MM, Buchanan KL, Klein ME, et al. A gutbrain neural circuit for nutrient sensory transduction. Science 2018;361:eaat5236.

120. Kimura I, Inoue D, Maeda T, et al. Short-chain fatty acids and ketones directly regulate sympathetic nervous system via G protein-coupled receptor 41 (GPR41). Proc Natl Acad Sci U S A 2011;108:8030-8035.

121. Montagner A, Korecka A, Polizzi A, et al. Hepatic circadian clock oscillators and nuclear receptors integrate microbiome-derived signals. Sci Rep 2016;6:20127.

122. Parada Venegas D, De la Fuente MK, Landskron G, et al. Short chain fatty acids (SCFAs)-mediated gut epithelial and immune regulation and its relevance for inflammatory bowel diseases. Front Immunol 2019;10:277.

123. Kelly JR, Kennedy PJ, Cryan JF, Dinan TG, Clarke G, Hyland NP. Breaking down the barriers: the gut microbiome, intestinal permeability and stress-related psychiatric disorders. Front Cell Neurosci 2015;9:392.

124. Brial F, Le Lay A, Dumas M-E, Gauguier D. Implication of gut microbiota metabolites in cardiovascular and metabolic diseases. Cell Mol Life Sci 2018;75:3977-3990.

125. Bien J, Palagani V, Bozko P. The intestinal microbiota dysbiosis and Clostridium difficile infection: is there a relationship with inflammatory bowel disease? Therap Adv Gastroenterol 2013;6:53-68.

126. Woting A, Blaut M. The intestinal microbiota in metabolic disease. Nutrients 2016;8:202.

127. Parekh P, Arusi E, Vinik A, Johnson D. The role and influence of gut microbiota in pathogenesis and management of obesity and metabolic syndrome. Front Endocrinol 2014;5:47.

128. Pavlov VA, Tracey KJ. The vagus nerve and the inflammatory reflex-linking immunity and metabolism. Nat Rev Endocrinol 2012;8:743-754.

129. Sherwin E, Dinan TG, Cryan JF. Recent developments in understanding the role of the gut microbiota in brain health and disease. Ann N Y Acad Sci 2017;30:10191041.

130. Purkayastha S, Cai D. Neuroinflammatory basis of metabolic syndrome. Mol Metab 2013;2:356-363.

131. Milani C, Ticinesi A, Gerritsen J, et al. Gut microbiota composition and Clostridium difficile infection in hospitalized elderly individuals: a metagenomic study. Sci Rep 2016;6:25945.

132. de la Fuente-Nunez C, Meneguetti BT, Franco OL, Lu TK. Neuromicrobiology: how microbes influence the brain. ACS Chem Neurosci 2018;9:141-150.

133. Tremlett H, Bauer KC, Appel-Cresswell S, Finlay BB, Waubant E. The gut microbiome in human neurological disease: a review. Ann Neurol 2017;81:369-382.

134. Sampson TR, Debelius JW, Thron T, et al. Gut microbiota regulate motor deficits and neuroinflammation in a model of Parkinson's disease. Cell 2016;167:1469-1480. 
135. Gao J, Xu K, Liu H, et al. Impact of the gut microbiota on intestinal immunity mediated by tryptophan metabolism. Front Cell Infect Microbiol 2018;8:13.

136. Lim CK, Fernandez-Gomez FJ, Braidy N, et al. Involvement of the kynurenine pathway in the pathogenesis of Parkinson's disease. Prog Neurobiol 2017;155:76-95.

137. Song P, Ramprasath T, Wang H, Zou M-H. Abnormal kynurenine pathway of tryptophan catabolism in cardiovascular diseases. Cell Mol Life Sci 2017;74:2899-2916.

138. Lovelace MD, Varney B, Sundaram G, et al. Recent evidence for an expanded role of the kynurenine pathway of tryptophan metabolism in neurological diseases. Neuropharmacology 2017;112:373-388.

139. Perez-Pardoa P, Kliesta T, Dodiyab H, et al. The gut-brain axis in Parkinson's disease: possibilities for food-based therapies. Eur J Pharmacol 2017;617:86-95.

140. Parashar A, Udayabanu M. Gut microbiota: implications in Parkinson's disease. Parkinsonism Relat Disord 2017; 38:1-7.

141. Chen SG, Stribinskis V, Rane MJ, et al. Exposure to the functional bacterial amyloid protein curli enhances alphasynuclein aggregation in aged Fischer 344 rats and Caenorhabditis elegans. Sci Rep 2016;6:34477.

142. Wang Z, Klipfell E, Bennett B, et al. Gut flora metabolism of phosphatidylcholine promotes cardiovascular disease. Nature 2011;472:57-63.

143. Kitai T, Kirsop J, Tang W. Exploring the microbiome in heart failure. Curr Heart Fail Rep 2016;13:103-109.

144. Komaroff AL. The microbiome and risk for atherosclerosis. JAMA 2018;319:2381-2382.

145. Jie Z, Xia H, Zhong S-L, et al. The gut microbiome in atherosclerotic cardiovascular disease. Nat Commun 2017;8:845.

146. Mazidi M, Rezaie P, Kengne A, Mobarhan M, Ferns G. Gut microbiome and metabolic syndrome. Diabetes Metab Syndr 2016;10S:S150-S157.

147. Fu J, Bonder MJ, Cenit MC, et al. The gut microbiome contributes to a substantial proportion of the variation in blood lipids. Circ Res 2015;117:817-824.

148. Olsen I, Taubman MA, Singhrao SK. Porphyromonas gingivalis suppresses adaptive immunity in periodontitis, atherosclerosis, and Alzheimer's disease. J Microbiol 2016;8:33029.

149. O'Mahony SM, Dinan TG, Cryan JF. The gut microbiota as a key regulator of visceral pain. Pain 2017;158:S19-S28.

150. Gonzalez A, Hyde E, Sangwan N, Gilbert JA, Viirre E, Knight R. Migraines are correlated with higher levels of nitrate-, nitrite-, and nitric oxide-reducing oral microbes in the American Gut Project Cohort. mSystems 2016;1: e00105-e00116.

151. Arora HC, Eng C, Shoskes DA. Gut microbiome and chronic prostatitis/chronic pelvic pain syndrome. Ann Transl Med 2017;5:30.

152. Horta-Baas G, Romero-Figueroa M, Montiel-Jarquin A, Pizano-Zarate M, Garcia-Mena J, Ramirez-Duran N. Intestinal dysbiosis and rheumatoid arthritis: a link between gut microbiota and the pathogenesis of rheumatoid arthritis. J Immunol Res 2017;2017:4835189.

153. Bicknell B, Liebert A, Johnstone D, Kiat H. Photobiomodulation of the microbiome: implications for metabolic and inflammatory diseases. Lasers Med Sci 2018; 34:317-327.

154. Blivet G, Meunier J, Roman FJ, Touchon J. Neuroprotective effect of a new photobiomodulation technique against $\mathrm{A} \beta 25-35$ peptide-induced toxicity in mice: novel hypothesis for therapeutic approach of Alzheimer's disease suggested. Alzheimers Dement 2018;4:54-63.

155. Auboyer L, Meunier J, Roman F, Touchon J, Blivet G. Designing a unique photobiomodulation treatment protocol by assessing efficient photonic and magnetic emission parameters on an Alzheimer's disease animal model. In: SPIE Photonics West. San Francisco, 2019.

156. Imhann F, Vila AV, Bonder MJ, et al. Interplay of host genetics and gut microbiota underlying the onset and clinical presentation of inflammatory bowel disease. Gut 2018;67:108-119.

157. Ottman N, Geerlings SY, Aalvink S, de Vos WM, Belzer C. Action and function of Akkermansia muciniphila in microbiome ecology, health and disease. Best Pract Res Clin Gastroenterol 2017;31:637-642.

158. Vandeputte D, Falony G, Vieira-Silva S, et al. Prebiotic inulin-type fructans induce specific changes in the human gut microbiota. Gut 2017;66:1968-1974.

159. Koliada A, Syzenko G, Moseiko V, et al. Association between body mass index and Firmicutes/Bacteroidetes ratio in an adult Ukrainian population. BMC Microbiol 2017; 17:120.

160. Mariat D, Firmesse O, Levenez F, et al. The Firmicutes/Bacteroidetes ratio of the human microbiota changes with age. BMC Microbiol 2009;9:123.

161. Patra V, Laoubi L, Nicolas JF, Vocanson M, Wolf P. A perspective on the interplay of ultraviolet-radiation, skin microbiome and skin resident memory TCRalphabeta+ cells. Front Med (Lausanne) 2018;5:166.

162. Hamblin MR. Ultraviolet irradiation of blood: "the cure that time forgot"? Adv Exp Med Biol 2017;996:295-309.

163. Wu X, Hu X, Hamblin MR. Ultraviolet blood irradiation: is it time to remember "the cure that time forgot"? J Photochem Photobiol B 2016;157:89-96.

164. Karu TI, Tiphlova OA, Letokhov VS, Lobko YV. Stimulation of E. coli growth by laser and incoherent red light. Il Nuoyo Cimento 1983;2:1138-1144.

165. Karu T. Photobiology of low-power laser effects. Health Phys 1989;56:691-704.

166. Huang YY, Chen AC, Carroll JD, Hamblin MR. Biphasic dose response in low level light therapy. Dose Response 2009; 7:358-383.

167. Huang YY, Sharma SK, Carroll J, Hamblin MR. Biphasic dose response in low level light therapy - an update. Dose Response 2011;9:602-618.

168. de Sousa NTA, Gomes RC, Santos MF, Brandino HE, Martinez R, de Jesus Guirro RR. Red and infrared laser therapy inhibits in vitro growth of major bacterial species that commonly colonize skin ulcers. Lasers Med Sci 2016; 31:549-556.

169. Fukuda TY, Tanji MM, Silva SR, Sato MN, Plapler H. Infrared low-level diode laser on inflammatory process modulation in mice: pro-and anti-inflammatory cytokines. Lasers Med Sci 2013;28:1305-1313.

170. Fernandes KP, Souza NH, Mesquita-Ferrari RA, et al. Photobiomodulation with $660-\mathrm{nm}$ and $780-\mathrm{nm}$ laser on activated J774 macrophage-like cells: effect on M1 inflammatory markers. J Photochem Photobiol B 2015;153: 344-351.

171. Johnstone D, El Massri N, Moro C, et al. Indirect application of near infrared light induces neuroprotection in a mouse model of parkinsonism-an abscopal neuroprotective effect. Neuroscience 2014;274:93-101. 
172. Johnstone DM, Mitrofanis J, Stone J. Targeting the body to protect the brain: inducing neuroprotection with remotely-applied near infrared light. Neural Regen Res 2015;10:349-351.

173. Stone J, Johnstone D, Mitrofanis J. The helmet experiment in Parkinson's disease: an observation of the mechanism of neuroprotection by near infra-red light. In: 9th WALT Congress. Gold Coast, Australia, 2013.

174. Kim B, Mitrofanis J, Stone J, Johnstone DM. Remote tissue conditioning is neuroprotective against MPTP insult in mice. IBRO Rep 2018;4:14-17.

175. Paramsothy S, Kamm M, Kaakoush N, et al. Multidonor intensive faecal microbiota transplantation for active ulcerative colitis: a randomised placebo-controlled trial. Lancet 2017;389:1218-1228.

176. Sun M-F, Zhu Y-L, Zhou Z-L, et al. Neuroprotective effects of fecal microbiota transplantation on MPTP- induced Parkinson's disease mice: gut microbiota, glial reaction and TLR4/TNF- $\alpha$ signaling pathway. Brain Behav Immun 2018;70:48-60.

Address correspondence to: Ann Liebert, PhD Australasian Research Institute

185 Fox Valley Road Wahroonga 2076

New South Wales Australia

E-mail: ann.liebert@sah.org.au

Received: January 25, 2019. Accepted after revision: June 18, 2019. Published online: October 7, 2019 